\title{
The effect of low flow anesthesia with sevoflurane on oxidative status
}

\author{
A prospective, randomized study
}

Hülya Kaşıkara, MD, PhD, Ayça T. Dumanlı Özcan, MD, PhD, Cemile K. Biçer, MD, PhD, Almila Şenat, MD, PhD, Abdüssamet Yalçın, MD, PhD, Cemile Altın, MD, PhD, Şemsi Mustafa Aksoy, MD, PhD, Abdülkadir But, MD, PhD.

\begin{abstract}

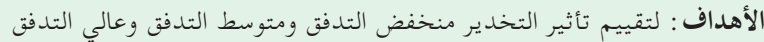

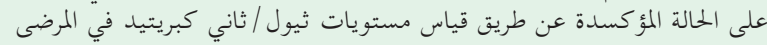
الذين يخضعون لعملية جراحية.

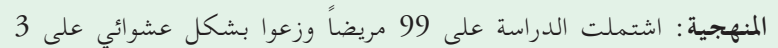

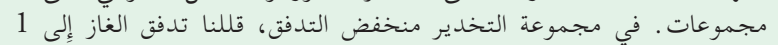

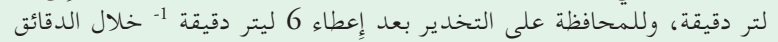

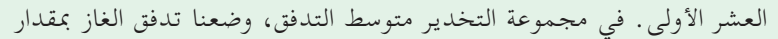

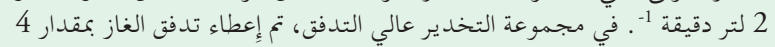

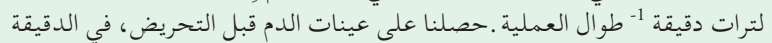

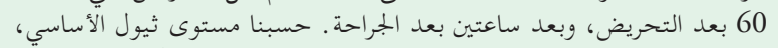

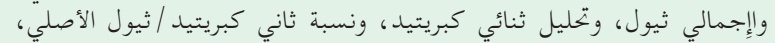

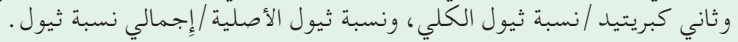

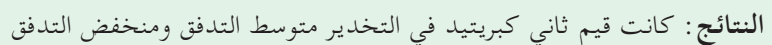

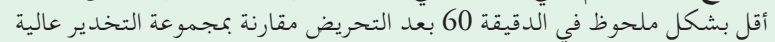

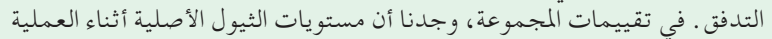

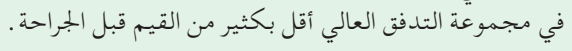

الحلاصة: لوحظ أن التخدير منخفض التدفق بالسيفوفلوران يقلل الضرر

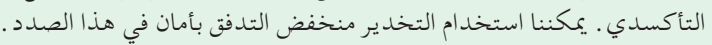

Objectives: To assess the impact of low-flow, mid-flow, and high-flow sevoflurane anesthesia on the oxidative state by measuring thiol/disulfide levels in patients undergoing surgery.

Methods: The study included 99 patients randomly assigned to 3 groups. In the low-flow anesthesia group, the fresh gas flow was diminished to $1 \mathrm{~L} \cdot \mathrm{min}^{-1}$ for anesthesia maintenance after $6 \mathrm{~L} \cdot \mathrm{min}^{-1}$ was administered for the first 10 minutes. In the mid-flow anesthesia group, fresh gas flow was applied as $2 \mathrm{~L} \cdot \mathrm{min}^{-1}$. In the high-flow anesthesia group, the fresh gas flow was administered as $4 \mathrm{~L} \cdot \mathrm{min}^{-1}$ throughout the operation. Blood samples were obtained before induction, at the 60th minute after induction, and at 2 hours postoperatively. Native thiol, total thiol, disulfide analyzed and disulfide/ native thiol percentage, disulfide/total thiol percentage, and native thiol/total thiol percentage were calculated.
Results: Disulfide values in mid-flow and low-flow anesthesia were significantly lower at the 60th minute after induction compared to the high-flow anesthesia group. In the group evaluations, intraoperative native thiol levels in the high-flow group were found to be substantialy lower than preoperative values.

Conclusion: It was sighted that low-flow anesthesia with sevoflurane prohibited oxidative damage. It was concluded that low flow anesthesia can be utilized safely in this respect.

Keywords: low-flow anesthesia, sevoflurane, thiol/ disulfide homeostasis, oxidative status

Saudi Med J 2022; Vol. 43 (3): 227-235

doi: 10.15537/smj.2022.43.3.20210876

From the Department of Anesthesiology and Reanimation (Kaşıara, Dumanl Ozcan), Ankara City Hospital, from the Department of Medical Biochemistry (Biçer), School of Medicine; from the Department of General Surgery (Yalçin); from the Department of Anesthesiology and Reanimation (Aksoy, But); Ankara Yildirum Beyazut University, and from the Department of Anesthesiology and Reanimation (Altin),

Hacettepe University, Ankara, Turkey.

Received 29th October 2021. Accepted 8th February 2022.

Address correspondence and reprint request to: Dr. Hülya Kaşıkara, Department of Anoesthesiology and Reanimation, Ankara City Hospital, Ankara, Turkey. E-mail: dr.hulyakasikara@gmail.com ORCID ID: https://orcid.org/0000-0002-4312-8560

$T$ he anesthesia technique carried out in surgical interventions, the duration of the procedure, and the surgical intervention itself impact the immune functions and cause an increase in reactive oxygen species (ROS) in metabolism. Reactive oxygen species may contribute to postoperative disorders by targeting biomolecules such as lipid, carbohydrate, protein, and DNA of cells. ${ }^{1-4}$ Therefore, the oxidant and antioxidant activities of anesthetic agents could be of 
clinical significance. Inhalation agents are widely used in the maintenance of general anesthesia, and studies have revealed that these anesthetics cause various changes in the antioxidant defence mechanisms against oxidative stress. ${ }^{5}$ Thiols found in human plasma are a class of organic compounds consisting of a sulfhydryl- containing sulfur atom and a hydrogenbonded carbon atom. Thiols in plasma consist mainly of albumin and other protein thiols and small amounts of low molecular weight thiols. ${ }^{6}$ Under oxidative stress conditions, thiols can undergo oxidation reactions via oxidants and generate disulfide bonds. The degradation of these disulfide bonds to thiol groups allows dynamic thiol-disulfide homeostasis. It has been reported that thiol oxidation might contribute to disease with little or no dependence on free radicals. ${ }^{7}$

Low-flow anesthesia is a technique of inhalation anesthesia, which is carried out via a semi-closed rebreathing system with a rebreathing fraction of at least $50 \%$. It plays an important role in modern anesthesia practice due to advantages such as preventing the waste of oxygen and volatile anesthetics, as well as reducing the amount of waste gas emitted to the atmosphere and the environment. With low-flow anesthesia, the total amount of anesthetic gas vaporized is reduced, thereby helping to increase mucociliary clearance in the respiratory system, maintain body temperature, and reduce fluid loss by preserving heat and humidity in the inhaled fresh gas mixture. ${ }^{8}$ The oxidative and cytotoxic effects of inhalation agents used in general anesthesia have been previously investigated through thiol-disulfide homeostasis, but the effect of low-flow and high flow anesthesia with sevoflurane on thioldisulfide homeostasis has not been investigated. ${ }^{9,10}$ The aim of this study was to assess the effect of low, mid, and high flow sevoflurane anesthesia on the oxidative state by measuring thiol/disulfide levels in patients who underwent total thyroidectomy operation under elective conditions. A further goal of the study is to observe whether there is a substantial difference between the groups in blood pressure and heart rate follow-ups in the intraoperative period.

Methods. This prospective and randomized study included a total of 105 patients classified as American Society of Anesthesiologists (ASA) stages I-II, who were scheduled to undergo elective total thyroidectomy

Disclosure. Authors have no conflict of interests, and the work was not supported or funded by any drug company. operation. The study was carried out in Atatürk Training and Research Hospital, Ankara, Turkey, from February 2017 until January 2018. Approval from the Ethics Committee of Yıldırım Beyazıt University, Ankara, Turkey, was granted and informed written consent were obtained from the patients. The principles of the Declaration of Helsinki were obeyed at all stages.

The duration of operation was restricted to 60-120 minutes. Patients with diabetes mellitus, coronary artery disease, liver and kidney parenchyma disease, neurological disease, oncological disease, severe anemia, pregnancy or the lactation period, smoking history, history of vitamin and antioxidant medication use, such as, ascorbic acid, tocopherol, zinc, selenium, and those with potentially difficult intubation due to body mass index (BMI) of $>35 \mathrm{~kg} / \mathrm{m}^{2}$ were excluded from the study. An anesthetic machine (DatexOhmeda (GE) S/5 Avance Anesthesia Machine, USA) equipped for low-flow anesthesia was utilized in the operating room and soda-lime (Sorbo-lime, Berkim, Turkey) was used as a $\mathrm{CO}_{2}$ absorber. Every morning, the anesthesia machine was checked with a routine control test and the soda-lime was replaced. Using the sealed envelope randomisation method, the patients were assigned to one of 3 groups. Group 1 was the high-flow group, which was administered high-flow anesthesia during the maintenance of anesthesia. Group 2 was the mid-flow group, which was administered mid-flow anesthesia, and Group 3 was the low-flow group, which was administered low-flow anesthesia during the maintenance of general anesthesia. No patient received premedication before being taken to the operating table. Patient monitorisation included heart rate (HR), peripheral oxygen saturation $\left(\mathrm{SpO}_{2}\right)$, mean arterial pressure (MAP), and electrocardiography (ECG). Vascular access was established in all patients with a 22-gauge angiocatheter from the antecubital region in the left arm. After a $5 \mathrm{ml}$ blood sample was obtained into a biochemistry tube, isotonic infusion was started. To achieve anesthesia induction, $1 \mathrm{mg} \cdot \mathrm{kg}^{-1}$ of lidocaine (Aritmal \% $2100 \mathrm{mg} 5 \mathrm{ml} 5$ ampul, Osel ${ }^{\oplus}$, Istanbul, Turkey), 2 mcg. $\mathrm{kg}^{-1}$ fentanyl (Fentanyl Citrate, Abbott Lab. North Chicago, USA), $2.5 \mathrm{mg} \cdot \mathrm{kg}^{-1}$ propofol (1\% Fresenius $200 \mathrm{mg} / 20 \mathrm{ml} 5$ amp. Fresenius Kabi AB. Sweden), and for muscle relaxation, $0.6 \mathrm{mg} . \mathrm{kg}^{-1}$ rocuronium bromide (Esmeron $50 \mathrm{mg} 5 \mathrm{ml}$. Merck Sharp Dohme N.V.Organon, Holland) were administered to all patients. Pre-oxygenation with $100 \%$ oxygen was applied for 2 minutes with a face mask, then orotracheal intubation was carried out. Tidal volume was adjusted as 6-8 ml.kg-1 and respiratory frequency as 10-12 min-1. End-Tidal CO2 maintained between 35-40 
$\mathrm{mmHg}$. The patients were supported with soft pillows under the neck and shoulders, and a suitable position for surgery was achieved. Second vascular access was opened in all patients from the dorsal of the left hand, and fluid infusion was continued from this site. The vascular access in the antecubital region was preserved only for blood sampling. All patients were administered 1 mg.kg-1 tramadol (Madol 100 Mg/2ml Ampul Koçak Far. Kim. San. A.Ş Üsküdar/Istanbul) as a preemptive analgesic and $4 \mathrm{mg}$ ondansetron (Emeset $8 \mathrm{mg} / 4 \mathrm{ML} \mathrm{IM} /$ IV Koçak Far. Kim. San. A.Ş. Üsküdar/Istanbul) as an antiemetic. A 0.9-1 MAC sevoflurane (Forane, Abbott Lab., England) in a 40:60\% $\mathrm{O}_{2} \mathrm{~N}_{2} \mathrm{O}$ (nitrous oxide) mixture was administered to all patients for anesthesia maintenance. In the low-flow group, the fresh gas flow (FGF) was reduced to $1 \mathrm{~L} \cdot \mathrm{min}^{-1}$ after a $6 \mathrm{~L} \cdot \mathrm{min}^{-1}$ was administered for the first 10 minutes. In the mid-flow group, the FGF was administered as $2 \mathrm{~L}$. $\mathrm{min}^{-1}$ throughout the operation, and in the high-flow group, the FGF was administered as $4 \mathrm{~L} \cdot \mathrm{min}^{-1}$ throughout the operation. In the low-flow group, sevoflurane and nitrous oxide were discontinued nearly 10 minutes before extubation, and ventilation was started at $6 \mathrm{~L} \cdot \mathrm{min}^{-1}$ with $100 \%$ oxygen. Neuromuscular blockade was reversed by administering $0.04 \mathrm{mg} / \mathrm{kg}$ iv neostigmine (Neostigmine $0.5 \mathrm{Mg} / \mathrm{Ml}$ Injectable Solution, Adeka İlaç Sanayi ve Ticaret A.Ş Şişli/Istanbul) and $0.02 \mathrm{mg} / \mathrm{kg}$ iv atropine (Atropin Biosel $0.5 \mathrm{mg}$ ampul,OSEL İlaç San. ve Tic. A.Ş Beykoz/ Istanbul). The patient was extubated when the criteria were met for tracheal extubation (respiratory rate with spontaneous breathing $>8$, minimum tidal volume of $6 \mathrm{~mL} / \mathrm{kg}$ ). Hemodynamic parameters (MAP, HR) were recorded at pre-induction, post-induction, and at 5, 10, 15, 30, 60, and 90 minutes post-intubation. Blood samples were obtained from all patients before induction (T1), at 60 minutes after general anesthesia (T2), and at the end of the postoperative 2 nd hour (T3). The samples were centrifuged at $2000 \mathrm{~g}$ for 10 minutes and then kept at $-80^{\circ} \mathrm{C}$ until the time of analysis. When a sufficient number of patients was reached, the thiol/ disulfide levels were measured from the collected blood samples.

The automatic spectrophotometric method, as described by Erel et $\mathrm{al}^{11}$, was utilized for the measurement of thiol/disulfide tests. In this method, first, free functional thiol groups were formed by reducing the disulfide bonds with sodium borohydride. To avoid the reduction of 5,5'-dithio-bis-(2-nitrobenzoic) (DTNB) acid, the reducing sodium borohydride in the field was removed with formaldehyde. All of the thiol groups were formed after reacting with DTNB. The dynamic disulfide level was determined by calculating half the difference between total thiols and natural thiols.
After determining the natural thiols $(-\mathrm{SH})$, total thiols $(-\mathrm{SH}+-\mathrm{SS})$, and disulfide (-SS) levels, the disulfide/ total thiol percentage (-SS/-SH + -SS), disulfide/ natural thiol percentage $(-S S /-S H)$, and natural thiol/ total thiol percentage $(-\mathrm{SH} /-\mathrm{SH}+-\mathrm{SS})$ were calculated. Measurements were carried out using an automated chemistry analyzer (Cobas 501, Rochen Diagnostics, Mannheim, Germany). The obtained values were expressed as $\mu \mathrm{mol} / \mathrm{L}$.

The primary outcome aimed for in this study was to establish whether or not there is a significant difference in thiol/disulfide homeostasis parameters measured at T2 or T3 times in high-flow anesthesia and low-flow anesthesia groups compared to the preoperative $\mathrm{T} 1$ time. Based on disulfide T2 values, the power analysis was carried out using G*Power 3.1.9.7 software (Franz Foul, Universitat Kiel, Germany); $\mathrm{n}=82(\mathrm{n} 1=32, \mathrm{n} 2=25$, $n 3=25), \alpha=0.05$, effect size $(f)=0.4$; power $=89.9 \%$ (The effect size was accepted as " $\mathrm{f}=0.4$ " which was Cohen standardized).

Statistical analysis. Continuous variables were provided as mean \pm standard deviation (SD) values. categorical variables were provided as numbers (n) and percentage (\%). In the within-group analysis of permanent variables, harmony of the data to normal dispersion was appraised with the KolmogorovSmirnov goodness of fit test. The One-Way ANOVA test (post hoc: Bonferroni) was applied to the analysis of continuous variables between the 3 groups if data were normally distributed and if not, the Kruskal-Wallis test (post hoc: Mann-Whitney U-test) was used. The within-group analysis of time-dependent changes was applied using the repeated measures ANOVA test (post hoc: Bonferroni). The Chi-square test was enforced in the comparisons of categorical data. Data were investigated using the Statistical Package for the Social Sciences, version 22.0 (IBM Corp., Armonk, NY, USA). A $p$-value of $<0.05$ was considered significant.

Results. From the initial inclusion of 105 patients in the study, 5 patients who smoked and one patient who was predicted to have difficult intubation were excluded. The remaining 99 patients were randomly assigned to the 3 groups. After having been taken to the operating table, one patient was excluded from the analysis because of high blood pressure prior to induction. In the intraoperative period, iv prednisolone was administered to 13 patients at the request of the surgeon, and those cases were also excluded. Furthermore, 3 patients were excluded as the blood samples could not be quantified for analysis. The study was completed with blood samples from a total of 
82 patients (Figure 1). Statistically significant difference was not determined between the patient groups and demographic characteristics, duration of operation, or anesthesia ( $p>0.05$; Table 1$)$.

Mean HR values according to time (except 60th minute) were found to be statistically resemblanced among the groups ( $p>0.05$; Table 2$)$. The mean arterial pressure values according to time were found to be statistically resemblanced between the groups $(p>0.05$; Table 3).

In-group and between groups, comparisons of disulfide, total thiol, native thiol, disulfide/total thiol precentage, disulfide/natural thiol precentage, native thiol/total thiol precentage, and albumin levels were presented in Table 4. As a result of within-group analysis, significant differences were found between native thiol T1 and T2 levels in the high-flow anesthesia group ( $p=0.014)$. The native thiol level in the high-flow anesthesia group was determined to have decreased significantly at T2 compared to T1. When compared with the high-flow anesthesia group, levels of disulfide were found to be importantly reduced at T2 in the mid-flow and low-flow anesthesia groups $(p=0.01)$. It was identified that the disulfide/native thiol precentage level in the mid-flow anesthesia group decreased significantly at T2 compared to T1 $(p=0.038$; Table 4).

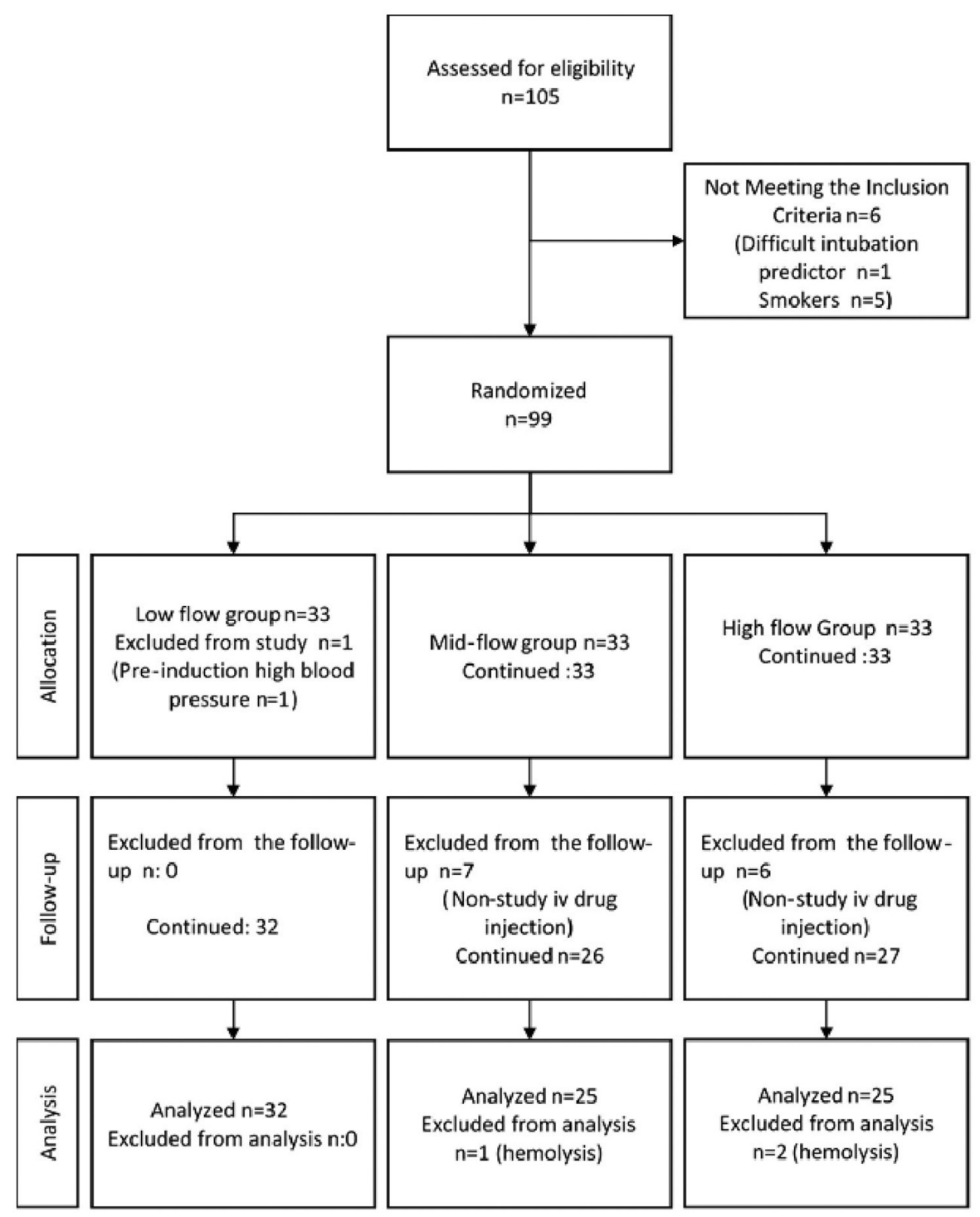

Figure 1 - Flow chart of the study. 
Table 1 - Comparison of the groups in terms of specific demographic and clinical characteristics.

\begin{tabular}{lcccc}
\hline Characteristics & Low-flow group (n=32) & $\begin{array}{c}\text { Mid-flow group (n=25) } \\
\text { Mean } \pm \text { SD }\end{array}$ & High-flow group (n=25) & $P$-value \\
\hline Age (year) & $41.40 \pm 12.96$ & $41.72 \pm 10.75$ & $43.81 \pm 11.72$ & $0.700^{*}$ \\
Body weight (kg) & $7.80 \pm 12.80$ & $69.08 \pm 10.97$ & $71.34 \pm 11.37$ & $0.757^{*}$ \\
Height (cm) & $165.44 \pm 7.41$ & $161.88 \pm 6.50$ & $162.75 \pm 8.83$ & $0.240^{*}$ \\
Gender (F/M), n & $17 / 8$ & $23 / 2$ & $26 / 6$ & $0.100^{* *}$ \\
ASA (I/II), n & $19 / 6$ & $20 / 5$ & $24 / 8$ & $0.900^{* *}$ \\
Duration of surgery (min) & $86.60 \pm 13.21$ & $93.00 \pm 17.97$ & $85.31 \pm 14.36$ & $0.149^{*}$ \\
Duration of anesthesia (min) & $97.40 \pm 13.08$ & $101.80 \pm 15.19$ & $95.63 \pm 14.65$ & $0.269^{*}$ \\
\hline
\end{tabular}

"One way ANOVA test, "Chi-square test, F/M: female/male, ASA: American Society of Anesthesiologists, SD: standard deviation

Table 2 - Comparison of heart rates (minute) within and between groups.

\begin{tabular}{lcccc}
\hline Time & Low-flow group (n=32) & $\begin{array}{c}\text { Mid-flow group }(\mathrm{n}=25) \\
\text { Mean } \pm \text { SD }\end{array}$ & High-flow group $(\mathrm{n}=25)$ & $P_{\text {-value }}{ }^{1}$ \\
\hline Baseline & $84.18 \pm 12.06^{\ddagger}$ & $79.00 \pm 11.42^{\ddagger}$ & $88.36 \pm 11.22^{\ddagger}$ & $0.112^{*}$ \\
Induction & $80.95 \pm 12.45$ & $81.81 \pm 12.60^{\ddagger}$ & $81.84 \pm 10.35^{\ddagger}$ & $0.965^{*}$ \\
Intubation & $88.77 \pm 10.10^{\ddagger}$ & $86.81 \pm 12.48^{\ddagger}$ & $92.47 \pm 15.63^{\ddagger}$ & $0.466^{*}$ \\
5th min & $79.54 \pm 8.48$ & $77.81 \pm 13.90$ & $83.68 \pm 14.11^{\ddagger}$ & $0.372^{*}$ \\
10th min & $76.68 \pm 9.02$ & $71.18 \pm 11.00$ & $75.73 \pm 13.74$ & $0.414^{*}$ \\
15th min & $72.81 \pm 8.81^{\ddagger}$ & $67.45 \pm 11.50^{\ddagger}$ & $69.94 \pm 10.37^{\ddagger}$ & $0.332^{*}$ \\
30th min & $71.45 \pm 7.35^{\ddagger}$ & $65.81 \pm 12.54^{\ddagger}$ & $67.00 \pm 9.26^{\ddagger}$ & $0.176^{*}$ \\
60th min & $71.09 \pm 6.26^{\ddagger, \neq}$ & $63.00 \pm 8.55^{\dagger, \neq}$ & $67.26 \pm 8.61^{\ddagger}$ & $0.021^{*}$ \\
90th min & $71.26 \pm 7.72^{\ddagger}$ & $66.50 \pm 11.08^{\ddagger}$ & $72.58 \pm 9.10^{\ddagger}$ & $0.249^{*}$ \\
$P$-value & $<0.001^{* *}$ & $<0.001^{* *}$ & $<0.001^{* *}$ & \\
\hline
\end{tabular}

"One-way ANOVA test (post-hoc: ${ }^{\dagger}$ Bonferroni), " repeated measures ANOVA test (post-hoc: ${ }^{\ddagger}$ Bonferroni), SD: standard deviation

Table 3 - Comparison of mean arterial pressures $(\mathrm{mmHg})$ within and between groups.

\begin{tabular}{|c|c|c|c|c|}
\hline \multirow[t]{2}{*}{ Time } & Low-flow group ( $\mathrm{n}=32)$ & Mid-flow group (n=25) & High-flow group $(\mathrm{n}=25)$ & $P$-value ${ }^{1}$ \\
\hline & \multicolumn{4}{|c|}{ Mean $\pm S D$} \\
\hline Baseline & $101.45 \pm 12.50^{\dagger}$ & $96.22 \pm 9.67$ & $105.00 \pm 8.21^{\dagger}$ & $0.146^{*}$ \\
\hline Induction & $83.27 \pm 10.98$ & $87.44 \pm 15.31$ & $89.58 \pm 11.31^{\dagger}$ & $0.261^{*}$ \\
\hline Intubation & $93.59 \pm 17.70$ & $90.88 \pm 15.50$ & $98.94 \pm 11.32$ & $0.383^{*}$ \\
\hline 5 th $\min$ & $85.13 \pm 10.50$ & $88.66 \pm 4.63$ & $88.94 \pm 16.00$ & $0.574^{*}$ \\
\hline 10th min & $84.54 \pm 8.94$ & $80.00 \pm 7.41$ & $82.70 \pm 14.36$ & $0.575^{*}$ \\
\hline 15th min & $84.13 \pm 10.59$ & $82.11 \pm 12.98$ & $84.88 \pm 15.32$ & $0.872^{*}$ \\
\hline 30th min & $78.77 \pm 9.04$ & $78.88 \pm 13.18$ & $81.88 \pm 12.17^{\dagger}$ & $0.655^{*}$ \\
\hline 60th min & $82.50 \pm 11.10$ & $86.00 \pm 10.38$ & $80.88 \pm 11.68^{\dagger}$ & $0.545^{*}$ \\
\hline 90th min & $85.46 \pm 11.05$ & $86.75 \pm 9.31$ & $88.53 \pm 9.64$ & $0.731^{*}$ \\
\hline$P$-value ${ }^{2}$ & $<0.001^{* *}$ & $0.260^{* *}$ & $<0.001^{* *}$ & \\
\hline
\end{tabular}

Discussion. The principle finding of the present study was that low-flow sevoflurane anesthesia reduced the oxidative load on metabolism. Oxidative damage was observed to be greater in high flow anesthesia and the antioxidant capacity was insufficient to prevent this. The operation process creates a certain oxidant level
(-SS) in metabolism. The more active and strong the antioxidant defence system is (natural thiol $[-\mathrm{SH}]$ and total thiol $[-\mathrm{SH}+-\mathrm{SS}])$, the less oxidative damage is expected. The disulfide level, as an indicator of oxidative damage, was determined to decrease significantly as the FGF decreased from high flow to mid-flow and low 
Table 4 - Comparison of the groups in terms of native thiol, total thiol, disulfide, disulfide/native thiol, disulfide/total thiol, native thiol/total thiol levels, albumin.

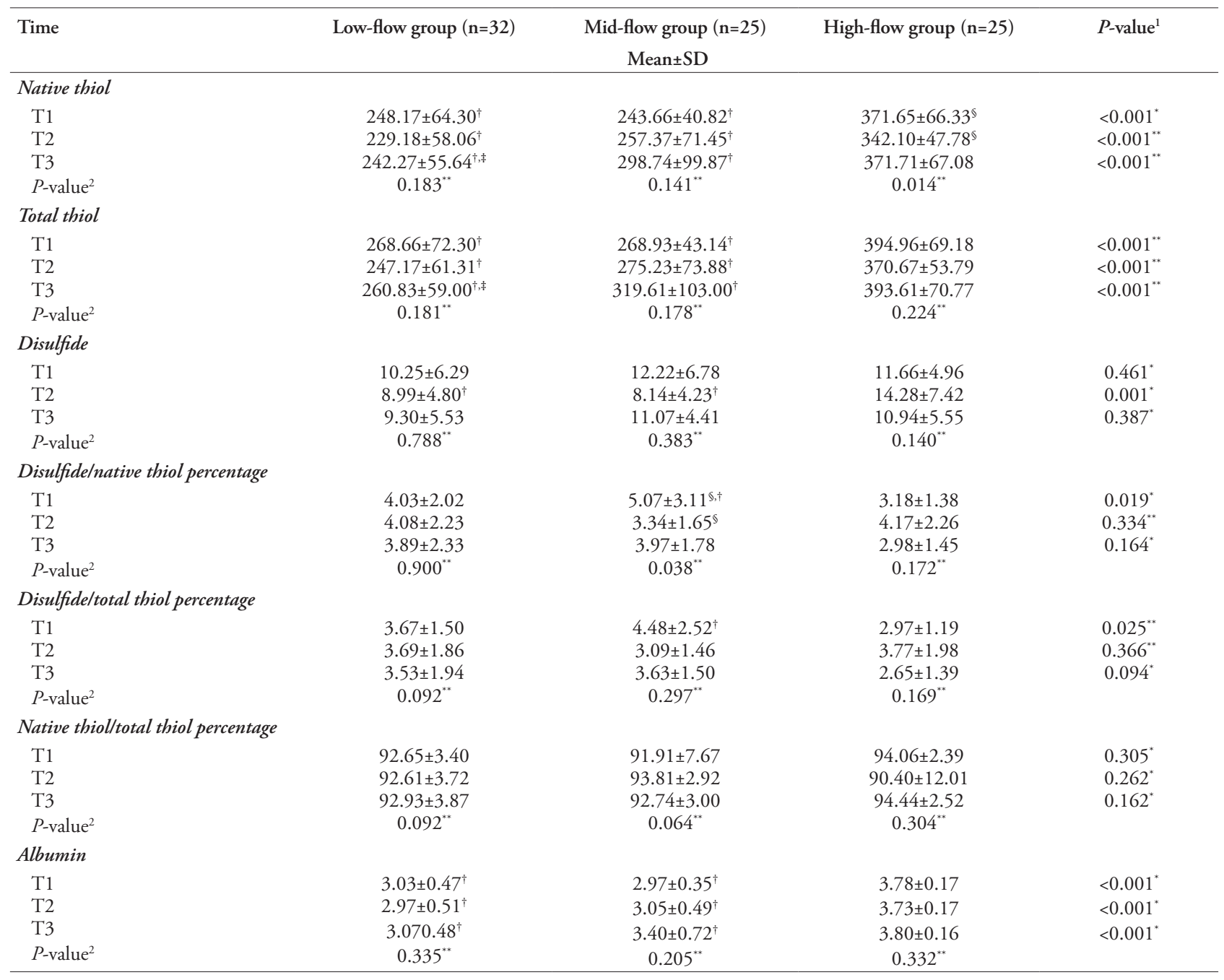

"Kruskal-Wallis test (Post hoc: Mann-Whitney U-test), "'One-Way ANOVA test (post hoc: Bonferroni), ${ }^{\$} p$-value ${ }^{2}$ of $<0.05$ (compared to T1-T2, native tiol, high-flow group), ${ }^{\dagger} p$-value ${ }^{1}$ of $<0.05$ (compared to high flow group, disulfide level at time T2 in mid-flow and low flow group), ${ }^{\$ \dagger} p$-value ${ }^{2}$ of $<0.05$ (T2 compared to T1, disulfide/native thiol percentage), T1: pre-induction, T2: 60th minute after induction, T3: postoperative 2nd hour, SD: standard deviation

flow (Table 4). The thiol-disulfide cycle was observed to accelerate in the high-flow group, but was not sufficient to prevent oxidative damage. It is well-documented that changes occur in every component of the immune system during anesthesia and surgery. These changes represent the overall physiological responses of the body. This linked primarily on the extent of the surgery and many factors such as the patient's health, age, medications, and blood transfusion. ${ }^{12}$ The surgical intervention itself is a factor for oxidative stress in the patient undergoing thyroid surgery. Likewise, general anesthesia induces inflammatory processes in patients. The inflammatory response, which begins with the production of leukocytes in alveolar macrophages, continues with the occurrence of mediators and free radicals. In the final stage, it results in the formation of peroxidation products that cause membrane damage. This may prolong the healing process by causing postoperative complications and hemodynamic changes, particularly in patients with organ dysfunction or co-morbidities. ${ }^{13}$

Each of the anesthetic gases and oxygen used in anesthesia can cause the formation of ROS in the organism. Oxygen is the central to all metabolic processes, but as a medication, it can cause toxicity in 
a time-dependent manner. Oxygen toxicity is caused when the partial pressure of oxygen exceeds the amount inhaled under normal atmospheric conditions. ${ }^{14,15}$ In numerous studies carried out with high-flow anesthesia, it has been demonstrated that anesthetic gas and oxygen consumption was significantly higher compared to low-flow anesthesia. ${ }^{16,17}$ Tissues exposed to high oxygen produce reactive oxygen. Oxidative cell damage often causes cells to die by disrupting their integrity, causing microvascular and alveolar disruption. Specifically, ROS, which are metabolites of oxygen consumption, can cause lung injury by disrupting the alveolarcapillary membrane. However, in some experimental studies, it has been displayed that antioxidant levels raised in parallel with the enhancement in oxidative stress markers in the lungs. ${ }^{18}$ Protein thiols are the main targets of ROS in vivo, and oxidative conversion and reduction of thiols to disulfides occurs for thioldisulfide exchange. ${ }^{19}$ The main target of ROS is the $-\mathrm{SH}$ groups of sulfur-containing amino acids such as cysteine and methionine. The $-\mathrm{SH}$ groups are oxidized when in the same environment as ROS and form reversible disulfide bonds. This is the initial indication of radicalmediated protein oxidation. ${ }^{20}$ When within-group variances were analyzed in the study, it was followed that there was a significant reduce in intraoperative native thiol compared to the preoperative value in the high-flow group. It was thought that the oxygen applied at high flow played a role in this. Studies have reported that sevoflurane protects against oxidative stress and inflammation through nitric oxide synthase activation and inhibition of nuclear factor kappa-B $(\mathrm{NF}-\mathrm{\kappa B})$, and suppresses cytokine release more than other volatile anesthetic gases. ${ }^{21}$ Previous studies have reported that operations carried out under anesthesia caused inflammatory responses in metabolism such as leukocytosis, neutrophilia, and lymphopenia. In some later studies, the ratios of neutrophil and platelet count to lymphocyte count have been utilized as markers of inflammatory response (platelet-lymphocyte ratio [PLR] and neutrophil-lymphocyte ratio [NLR]). Tanriverdi et $\mathrm{al}^{22}$ investigated the effect of low-flow anesthesia with desflurane on NLR and PLR in patients undergoing laparoscopic cholecystectomy, and reported that the inflammatory response was diminished meaningfully in the low flow group than in patients administered mid-flow desflurane anesthesia. In another study, Ozcan et $\mathrm{al}^{9}$ demonstrated via thiol-disulfide hemostasis parameters that the antioxidant properties of sevoflurane were significantly higher compared to desflurane. In another research, the efficacy of propofol and sevoflurane on the systemic and local inflammatory response during single lung ventilation in patients who underwent lung resection were compared, and it was shown that sevoflurane could not reduce the systemic inflammatory response, but reduced the local alveolar inflammatory response. ${ }^{23}$ Previous animal experiments have shown that sevoflurane was associated with physiological processes such as reducing free oxygen radicals, reducing inflammation by lowering the intracellular calcium level, and improving energy metabolism. ${ }^{24,25}$ In recent studies, sevoflurane has been shown to increase the level of ROS and pro-inflammatory cytokines in metabolism, thereby triggering the NF- $\kappa \mathrm{B}$ signaling pathway. This causes inflammatory cytokines to be relased, resulting in mitochondrial damage and cell death due to the increase in intracellular calcium. ${ }^{26,27}$ However, in a recently published article it was stated that the effects of general anesthesia on the immune system were not so substantial in healthy patients without comorbidities and in surgeries of shorter duration, and that the fluctuations in the immune system seen on the first postoperative day were mainly due to surgical trauma. ${ }^{28}$

In this study, the oxygen: $\mathrm{N}_{2} \mathrm{O}$ ratio used was 40:60 in all 3 groups to achieve an adequate depth of anesthesia in the maintenance of anesthesia. The $\mathrm{N}_{2} \mathrm{O}$ is the inhalation anesthetic with the most rapid onset of action. Some adverse effects may be experienced during the use of $\mathrm{N}_{2} \mathrm{O}$, one of which is that $\mathrm{N}_{2} \mathrm{O}$ oxidizes vitamin $\mathrm{B}_{12}$ and leads to a deficiency in the body. Vitamin $B_{12}$ is essential for the enzymes involved in DNA synthesis to function. It has been previously shown that long-term exposure to nitrous oxide leads to neurological and hematological deteriorations and causes deterioration in DNA synthesis. ${ }^{29}$ In the present study, the duration of anesthesia was limited to 90-120 minutes and nitrous oxide was used as a standard in all groups. The varying flow rates of anesthetic gases between the groups might have caused a difference in exposure to nitrous oxide, in which, the impact on the study results was undeniable.

During anesthesia, the patient's hemodynamic status generally can be affected by 3 factors: the method of anesthesia, the type of surgery, and the cardiovascular status of the patients. The last 2 factors were similar in the patients of the current study.

Another outcome investigated in this study, was to evaluate the effects of low-flow, mid-flow, and high-flow sevoflurane anesthesia on hemodynamic parameters. The findings revealed that the HR and mean blood pressure values did not carry out a considerable difference in the application of different FGF. Taş et $\mathrm{al}^{30}$ evaluated the effects of minimal flow sevoflurane and minimal flow desflurane anesthesia on hemodynamic 
parameters, organ function and blood gas in patients undergoing posterior spinal instrumentation and found that hemodynamic parameters were alike among the 2 groups. It was concluded that minimal FGF did not cause hemodynamic disturbance and can be used safely.

Study limitations. The patients included in the surgery were not selected according to the mean albumin value. Peroperative native thiol values were measured higher in the high-flow anesthesia group compared to the other 2 groups, which was attributed to the fact that although the albumin values in this group were within the reference range, they were higher than the albumin values in the mid-flow and low-flow anesthesia groups. Previous studies have demonstrated a positive relation between albumin and natural thiol $(\mathrm{r}=0.76, p=0.001)$. The serum thiol level was largely due to the cysteine residue, the 34th amino acid of albumin. ${ }^{31}$

When the literature was reviewed, many studies have indicated the positive impacts of low flow anesthesia in different aspects, but the relationship between low-flow anesthesia and oxidative state has not been the subject of research to date. The beginning point of the study, was that intraoperative high-flow or low-flow sevoflurane anesthesia may have different effects on oxidative stress in surgical procedures. The results of the study largely confirmed this hypothesis. Yet, in this area more research are needed with different anesthetic gases and different oxidative stress markers.

In conclusion, oxidative damage is a significant factor affecting the postoperative recovery process. The use of low-flow anesthesia in the intraoperative period, especially for patients with comorbidities, may reduce oxidative damage in the postoperative period and accelerate the healing process. The current study revealed that low-flow anesthesia with sevoflurane was effective in reducing oxidative damage in metabolism and did not create any difference in hemodynamic parameters, so it can be used safely.

Acknowledgment. The authors gratefully acknowledge Ms. Caroline Walker for English language editing.

\section{References}

1. Tsuchiya M, Shiomoto K, Mizutani K, Fujioka K, Suehiro K, Yamada T, et al. Reduction of oxidative stress a key for enhanced postoperative recovery with fewer complications in esophageal surgery patients: randomized control trial to investigate therapeutic impact of anesthesia management and usefulness of simple blood test for prediction of high-risk patients. Medicine (Baltimore) 2018; 97: e12845.

2. Lucio LMC, Braz MG, do Nascimento Junior P, Braz JRC, Braz LG. [Occupational hazards, DNA damage, and oxidative stress on exposure to waste anesthetic gases]. Braz J Anesthesiol 2018; 68: 33-41. [in Portuguese]
3. Stevens JL, Feelisch M, Martin DS. Perioperative oxidative stress: the unseen enemy. Anesth Analg 2019; 129: 1749-1760.

4. Yılmaz Doğru H, Benli İ, Doğru S. The oxidative/anti-oxidative effects of sevoflurane on reproductive system of females: an experimental study. Turk J Obstet Gynecol 2017; 14: 228-232.

5. Kundović SA, Rašić D, Popović L, Peraica M, Črnjar K. Oxidative stress under general intravenous and inhalation anaesthesia. Arh Hig Rada Toksikol 2020; 71: 169-177.

6. Turell L, Radi R, Alvarez B. The thiol pool in human plasma: the central contribution of albumin to redox processes. Free Radic Biol Med 2013; 65: 244-253.

7. Köseoğlu H, Alışık M, Başaran M, Tayfur Yürekli Ö, Solakoğlu T, Tahtacı M, et al. Dynamic thiol/disulphide homeostasis in acute pancreatitis. Turk J Gastroenterol 2018; 29: 348-353.

8. Varughese S, Ahmed R. Environmental and occupational considerations of anesthesia: a narrative review and update. Anesth Analg 2021; 133: 826-835.

9. Ozcan ATD, Doger C, Ozturk L, Yungul A, Kurtsahin M, Neselioglu S, et al. Comparison of the effects of sevoflurane and desflurane on thiol-disulfide homeostasis in patients undergoing laparoscopic cholecystectomy. Eurasian J Med 2019; 51: 70-74.

10. Karabayirli S, Surgit O, Kasikara H, Koca Bicer C, Ergin M, Irem Demircioglu $\mathrm{R}$, et al. The effects of adding ischemic preconditioning during desflurane inhalation anesthesia or propofol total intravenous anesthesia on pneumoperitoneuminduced oxidative stress. Acta Chir Belg 2017; 117: 36-44.

11. Erel O, Neselioglu S. A novel and automated assay for thiol/ disulphide homeostasis. Clin Biochem 2014; 47: 326-332.

12. Amodeo G, Bugada D, Franchi S, Moschetti G, Grimaldi $S$, Panerai $A$, et al. Immune function after major surgical interventions: the effect of postoperative pain treatment. J Pain Res 2018; 11: 1297-1305.

13. Toro-Pérez J, Rodrigo R. Contribution of oxidative stress in the mechanisms of postoperative complications and multiple organ dysfunction syndrome. Redox Rep 2021; 26: 35-44.

14. Singer M, Young PJ, Laffey JG, Asfar P, Taccone FS, Skrifvars MB, et al. Dangers of hyperoxia. Crit Care 2021; 25: 440.

15. Cronin WA, Forbes AS, Wagner KL, Kaplan P, Cataneo R, Phillips M, et al. Exhaled volatile organic compounds precedes pulmonary injury in a swine pulmonary oxygen toxicity model. Front Physiol 2019; 10: 1297.

16. Tollinche L, Tan K, Han A, Ojea L, Yeoh C. Analyzing volatile anesthetic consumption by auditing fresh gas flow: an observational study at an academic hospital. Int J Anesth Anesth 2018; 5: 064.

17. Glenski TA, Levine L. The implementation of low-flow anesthesia at a tertiary pediatric center: a quality improvement initiative. Paediatr Anaesth 2020; 30: 1139-1145.

18. Forman HJ, Zhang H. Targeting oxidative stress in disease: promise and limitations of antioxidant therapy. Nat Rev Drug Discov 2021; 20: 689-709.

19. Baba SP, Bhatnagar A. Role of thiols in oxidative stress. Curr Opin Toxicol 2018; 7: 133-139.

20. Ulrich K, Jakob U. The role of thiols in antioxidant systems. Free Radic Biol Med 2019; 140: 14-27.

21. Cruz FF, Rocco PR, Pelosi P. Anti-inflammatory properties of anesthetic agents. Crit Care 2017; 21: 67. 
22. Bingöl Tanrıverdi T, Tercan M, Güsun Halitoğlu A, Kaya A, Patmano G. Comparison of the effects of low-flow and normal-flow desflurane anaesthesia on inflammatory parameters in patients undergoing laparoscopic cholecystectomy. Turk J Anaesthesiol Reanim 2021; 49: 18-24.

23. Yuan JL, Kang K, Li B, Lu J, Miao MR, Kang X, et al. The effects of sevoflurane vs. propofol for inflammatory responses in patients undergoing lung resection: a meta-analysis of randomized controlled trials. Front Surg 2021; 8: 692734.

24. Zhou T, Guo S, Wang S, Li Q, Zhang M. Protective effect of sevoflurane on myocardial ischemia-reperfusion injury in rat hearts and its impact on HIF-1 $\alpha$ and caspase-3 expression. Exp Ther Med 2017; 14: 4307-4311.

25. Liu D, Jin X, Zhang C, Shang Y. Sevoflurane relieves hepatic ischemia-reperfusion injury by inhibiting the expression of Grp78. Biosci Rep 2018; 38: BSR20180549.

26. Wang CM, Chen WC, Zhang Y, Lin S, He HF. Update on the mechanism and treatment of sevoflurane-induced postoperative cognitive dysfunction. Front Aging Neurosci 2021; 13: 702231.
27. Huang H, Hu C, Xu L, Zhu X, Zhao L, Min J. The effects of hesperidin on neuronal apoptosis and cognitive impairment in the sevoflurane anesthetized rat are mediated through the

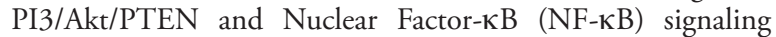
pathways. Med Sci Monit 2020; 26: e920522.

28. Jafarzadeh A, Hadavi M, Hassanshahi G, Rezaeian M, Vazirinejad R. General anesthetics on immune system cytokines: a narrative review article. Anesth Pain Med 2020; 10: e103033.

29. Campdesuner V, Teklie Y, Alkayali T, Pierce D, George J. Nitrous oxide-induced vitamin B12 deficiency resulting in myelopathy. Cureus 2020; 12: e9088.

30. Ayanoğlu Taş B, Şanlı Karip C, Abitağaoğlu S, Öztürk MC, Erdoğan Arı D. Comparison of minimal-flow sevoflurane versus desflurane anesthesia: randomized clinical trial. Braz J Anesthesiol 2022; 72: 77-82.

31. Bonanata J, Turell L, Antmann L, Ferrer-Sueta G, Botasini S, Méndez E, et al. The thiol of human serum albumin: acidity, microenvironment and mechanistic insights on its oxidation to sulfenic acid. Free Radic Biol Med 2017; 108: 952-962. 